\title{
DESENVOLVIMENTO DE UMA MATERIOTECA PARA PRODUÇÃO DE MODELOS FÍSICOS PARA $O$ LABORATÓRIO DE MODELAGEM
}

\author{
TAMIRES MACHADO PERES | IFSC \\ ROBERTO ANGELO PISTORELLO, M.SC. |IFSC
}

O projetar de produtos é uma atividade complexa e multidisciplinar que envolve a solução de diversos problemas para a sua conclusão. Durante a evolução deste processo, são utilizadas formas de representação, bi e/ou tridimensionais, dependendo da aplicação e da fase projetual.

Os modelos tridimensionais podem ser desenvolvidos com a combinação de diferentes materiais, que, de acordo com a sua finalidade, utilizam as características do material para simular o produto final, sendo que a escolha destes materiais nem sempre é trivial. O presente trabaIho parte da importância da Seleção de Materiais, no contexto de modelos tridimensionais no processo de Design de Produtos, com a intenção de auxiliar na minimização de falhas na construção de modelos físicos.

Para facilitar a seleção de materiais definiu-se o produto deste trabalho uma materioteca, que é um conjunto de materiais classificados por suas propriedades específicas, ordenados de forma a auxiliar o utilizador na escolha de um material ideal para o desenvolvimento de modelos durante o seu projeto.

Existem diversas materiotecas disponíveis, com finalidades distintas e não há um único padrão para a apresentação e disposição de informações para o usuário. Para compreensão e possível aplicação de um modelo de materioteca já existente, realizou-se uma análise de materiotecas com o objetivo de conhecer e entender a divisão e os modelos de categorias apresentados. Para isso, utilizou-se da pesquisa à materiotecas online.

A fim de identificar as necessidades dos usuários do produto, foi realizada uma pesquisa qualitativa com os professores e alunos do Curso Superior de Tecnologia em Design de Produto do Instituto de Ciência e Tecnologia de Santa Catarina - IFSC. Ainda, foi realizado um levantamento de todos os materiais utilizados no Laboratório de Modelagem do curso, a fim de comporem a materioca.
A materioteca desenvolvida e apresentada na Figura 1 possui painéis paralelos entre si que deslizam em trilhos, possibilitando a escolha e visualização de informações sobre os materiais, armazenadas em cards. Os cards, Figura 2 , são dispostos de forma frontal, permitindo a visualização de uma amostra de material, e diversas informações sobre o mesmo, como: peso, preço, flexibilidade, reciclabilidade, resistência, como usar e como não usar o material (dicas). O conjunto de informações fornecidas permite ao usuário a escolha da combinação de diferentes materiais para orientar a construção de modelos tridimensionais.

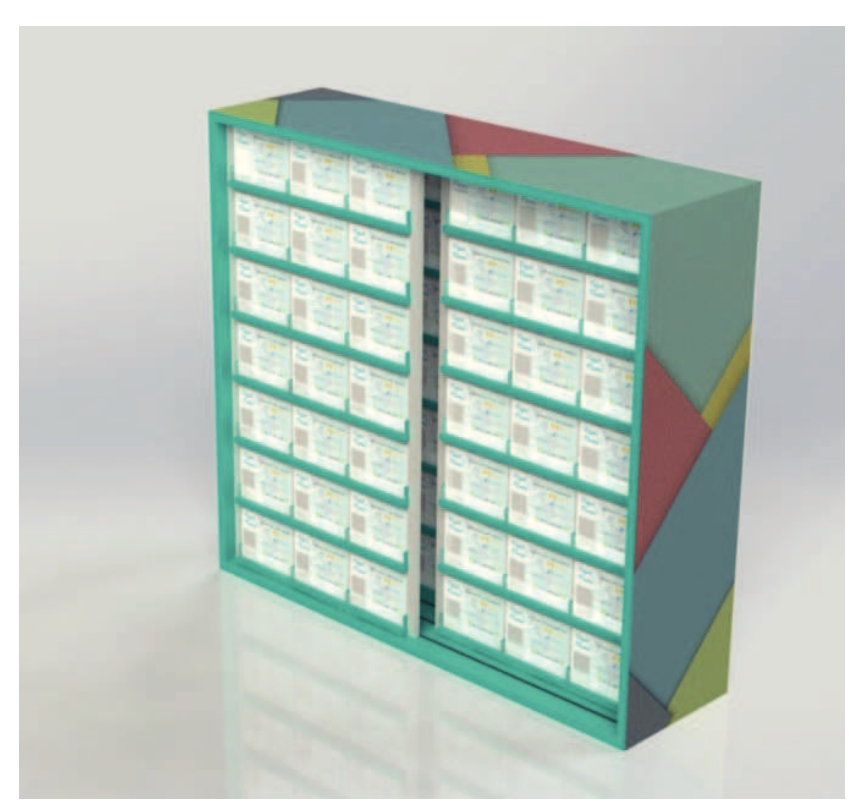

Figura 1: Materioteca para modelos físicos. Fonte: Elaborado pelos autores. 


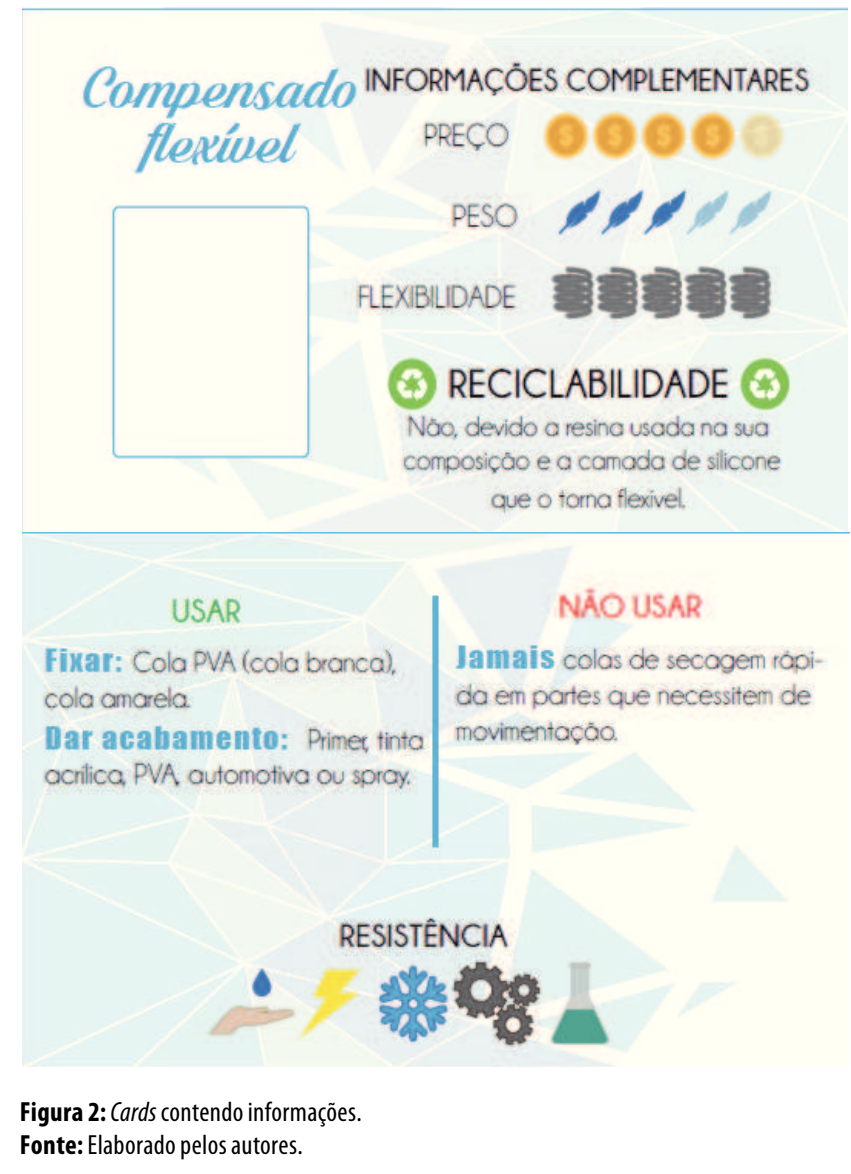

A utilização de painéis deslizantes e cards possibilita o armazenamento de 105 materiais diferentes, em um espaço reduzido, de aproximadamente $1 \mathrm{~m}^{2}$. Além disso, a materioteca abriga as informações de forma sucinta e direta, através de ícones, e possibilitam um processamento rápido da informação, reduzindo a possibilidade de erros no emprego de materiais, pelos alunos, durante a fase de modelamento e auxiliando na seleção e utilização de materiais sustentáveis. Para os professores do curso, a materioteca pode ser utilizada como material didático nas aulas relacionadas à modelagem física, auxiliando na compreensão da utilização dos materiais, fomentando a consciência do impacto ambiental dos materiais utilizados, correlacionando suas características físicas, como por exemplo, o impacto causado pela dificuldade de separação de materiais ao final do uso do modelo físico.

O projeto continua em evolução, uma vez que é exigida uma constante atualização dos materiais a serem inseridos na materioteca, para que a mesma não fique obsoleta. Ainda há o interesse em adicionar complementos a materioteca, como uma categoria de ferragens utilizadas em projeto de móveis, assim como outras categorias que venham a ser necessárias para construção de modelos físicos no Laboratório de Modelagem. 